\title{
O Método Ontopsicológico
}

\section{Patrícia Wazlawick}

\begin{abstract}
Resumo: Este artigo possui o objetivo geral de estudar o método ontopsicológico, a saber, o método bilógico. Metodologicamente, este é um estudo teórico e bibliográfico desenvolvido precisamente como um breve estado da arte na obra do Acadêmico Professor Antonio Meneghetti, em obras elencadas como fundamentais para a compreensão e a aplicação do método ontopsicológico. Como novidade ao estudo teórico, trazemos a apresentação e a descrição de uma cena in vivo de Antonio Meneghetti, por ocasião da explicação do conceito de nexo ontológico, proveniente, também da aplicação do método ontopsicológico. Com essa cena, temos a possibilidade de pensar, apresentar e visualizar aspectos relevantes do método ontopsicológico que serão previamente trabalhados em aspectos teóricos.
\end{abstract}

Palavras-chave: Método Ontopsicológico; método bilógico; Ontopsicologia; nexo ontológico.

\section{O Método Ontopsicológico}

Abstract: This article has the general objective of studying the ontopsychological method, namely, the bilogic method. Methodologically this is a theoretical and bibliographical study developed precisely as a brief state of the art in the work of the Academician Professor Antonio Meneghetti, in works listed as fundamental for the understanding and application of the ontopsychological method. As a novelty to the theoretical study, we present the presentation and description of an in vivo scene by Antonio Meneghetti, on the occasion of the explanation of the concept of ontological nexus, also coming from the application of the ontopsychological method. With this scene we have the possibility to think, present and to view relevants aspects of the ontopsychological method that will be previously worked on theoretical aspects.

Keywords: Ontopsychological Method; bilogic method; Ontopsychology; ontological nexus.

\section{El Método Ontopsicológico}

Resumen: Este artículo tiene el objetivo general de estudiar el método ontopsicológico, es decir, el método bilógico. Metodológicamente, se trata de un estudio teórico y bibliográfico desarrollado precisamente como un breve estado del arte en la obra del Académico Profesor Antonio Meneghetti, en obras señaladas como fundamentales para la comprensión y aplicación del método ontopsicológico. Como novedad en el estudio teórico, la presentación y descripción de una escena in vivo de Antonio Meneghetti, por motivo de la explicación del concepto del nexo ontológico, proveniente, también de la aplicación del método ontopsicológico. Con esta escena tenemos la posibilidad de pensar, presentar y visualizar aspectos relevantes del método ontopsicológico que se serán previamente trabajados en aspectos teóricos.

Palabras clave: Método Ontopsiológico; método bilógico Ontopsicología; nexo ontológico.

\section{Introdução}

A ideia de escrever este artigo nasce a partir de contínuos estudos na área da Ciência Ontopsicológica, da experimentação prática no dia a dia e da verificação e importância de formalizar um estudo sistemático acerca do método ontopsicológico. Nasce também do aspecto fundamental de que a Ontopsicologia, como ciência epistêmica e interdisciplinar, não 
substitui nenhuma outra ciência, mais que isso, coloca-se como complementar a todas as demais ciências e áreas de atuação humanistas-profissionais que desse conhecimento podem valer-se para produzir maior resultado de eficiência em prol do ser humano e de uma ciência verdadeiramente humana.

Metodologicamente, este é um estudo teórico e bibliográfico desenvolvido precisamente como um breve estado da arte na obra do Acadêmico Professor Antonio Meneghetti, em diversas obras elencadas como fundamentais para a compreensão e a aplicação do método ontopsicológico. Como novidade ao estudo teórico, trazemos a apresentação e a descrição de uma cena in vivo de Antonio Meneghetti, por ocasião da explicação do conceito de nexo ontológico - como maior diferencial e objetivo geral de formação do profissional egresso do Curso de Bacharelado em Ontopsicologia da $\mathrm{AMF}^{1}$ realizada em um residence ${ }^{2}$ conduzido pelo cientista em Lizari (Riga, Letônia) em outubro de 2012. Com essa cena, temos a possibilidade de pensar, apresentar e visualizar aspectos relevantes do método ontopsicológico, tais como serão verificados nos aspectos teóricos aqui trabalhados.

Porém, antes, traçamos uma breve passagem e olhar necessários sobre o Paradigma Positivista das Ciências e verificamos, de certa forma, como ele é insuficiente para compreender de modo exato a atividade psíquica, o ser humano nos seus aspectos subjetivos e a real objetividade da subjetividade necessária também, e principalmente, para fazer-se ciência.

\section{Fundamentação teórica}

\subsection{Um olhar sobre o Paradigma Positivista das Ciências e o emergir da Ontopsicologia}

Del Monte (1991), analisando o percurso das ciências modernas, a partir da obra de Thomas Kuhn, A Estrutura das Revoluções Científicas, verifica que o Positivismo e as

\footnotetext{
${ }^{1}$ Conforme Projeto Pedagógico de Curso (PPC) do Bacharelado em Ontopsicologia, da Faculdade Antonio Meneghetti, autorizado pela Portaria MEC $\mathrm{n}^{\circ} 563$ de 30 de setembro de 2014, publicada em Diário Oficial da União em 01 de outubro de 2014.

${ }^{2}$ Residence é um dos instrumentos de intervenção da Escola Ontopsicológica. "É um estágio full-immersion de três a sete dias dirigido a grupos selecionados de pessoas, durante o qual é efetuada uma verificação existencial. Enquanto instrumento psicossocial e ambiental, é preparado a partir da necessidade dos participantes de realizar um Eu lógico-histórico mais congruente a si mesmo e funcional dentro do espaço comunitário no qual eles convivem (...). Fazer um residence segundo a metodologia ontopsicológica, substancialmente, significa fazer uma verificação se o próprio estado de ser e da própria produção de vida é ou não funcional ao crescimento, ao bem-estar e à satisfação de toda a unidade de ação que se é. Portanto, verifica-se se o próprio modelo de vida além de ser sadio - está também em gestão eficiente e êxito vencedor (MENEGHETTI, 2012, p. 236).
} 
Ciências Naturais, com o seu paradigma dominante, não dão conta de entender e estudar a subjetividade do homem. Isto é, por essa via, mesmo que se tenha tentado, não é possível esse feito de modo completo.

Já advertia, Kuhn, a necessidade de um método, “...'um novo ponto de vista’ a partir do qual olhar não somente aquilo que é externo ('está fora de nós'), mas também aquilo que é interno" (KUHN, 2011 p. 15). Outro ponto importante é que, na pesquisa e no processo de conhecimento, nada deve ser impedido, nenhuma via aprioristicamente vetada: "existem problemáticas que, por quanto significativas e interessantes, não encontram colocação (nem resposta) no âmbito das ciências oficiais" (KUHN, 2011, p. 15), e esses pontos de compreensão já são salientados e destacados desde o início do séc. XX, com a emergência da Mecânica Quântica e a Física Nuclear por Heisenberg (1996, 2003, 2009, 2010, 2015a, 2015b), Santos (1990) e Bohr (1995).

E assim - não iremos retomar todo o percurso histórico e epistemológico das ciências ${ }^{3}$ - verifica-se que, em diversos momentos históricos, essa posição rígida do objetivismo científico, que exclui do seu âmbito aqueles conhecimentos que não se ajustam ao seu modelo e método de pesquisa, foi (e é) frequentemente criticada como reducionista (DEL MONTE, 1991). A ciência, frequentemente, torna-se um campo de luta - como já apresentava Kant (1979), em sua obra A crítica da razão pura -, definindo e determinando, por convenção, o que é científico e o que não é, o que pode ser estudado e como, e o que é válido nos cânones científicos.

Naquele momento, a solução dada foi que os conhecimentos deveriam ser baseados sobre a experiência, excluindo da ciência qualquer conhecimento que não fosse imediatamente ou mediatamente suscetível de experiência, a partir da aplicação técnica e verídica do método científico galileano ${ }^{4}$. Um dos pontos de discussão é que, no entanto, a experiência do cientista, nesse viés, baseia-se sobre a experiência sensória externa, ou o que seja, de todo modo, reconduzível a esta e por esta. Dessa forma, a experiência interna [do cientista], por ser considerada subjetiva, deveria ser descartada.

Foi assim que, por exemplo, "a fantasia, o sonho, a intuição, o sentimento, o símbolo foram relegados a outros mundos, tais como a literatura, a arte, as ciências ditas ocultas, à ficção científica" (DEL MONTE, 1991, p. 16). E, para alçar o status de ciência, a Psicologia começa a utilizar, de modo intenso, o método das Ciências Exatas e Ciências Naturais, adaptando-se. É de grande valor relembrar o que Sigmund Freud escreveu na Gradiva:

\footnotetext{
${ }^{3}$ Pois não é este nosso escopo neste artigo.

${ }^{4} \mathrm{O}$ método de maior credibilidade no mundo ocidental é o método científico a partir da formação de Galileu Galilei.
} 
os poetas são aliados preciosos, e o seu testemunho deve ser tomado em consideração, já que eles sabem, em geral, uma quantidade de coisas entre o céu e a terra que o nosso saber acadêmico nem mesmo suspeita. Particularmente, nas ciências do espírito eles de longe derrotaram a nós, comuns mortais, já que atingiram a fontes que não foram ainda abertas pela ciência (FREUD, 2015, s/p).

Já Edmund Husserl, alguns anos mais tarde, acusava o mesmo ponto. Na análise de Meneghetti (2015a), "Husserl, muito a propósito acusou o método científico de ter perdido a ligação com o mundo-da-vida e, por consequência, ele [o método científico] ${ }^{5}$ ficava avulso do verdadeiro significado" (p. 183). Dessa forma, o método científico alcançaria apenas uma parte do conhecimento, ou da forma e processo de conhecer. Não significa que seja errado, mas seria incompleto, deduz-se.

Pois bem, o princípio base do método científico é o princípio de causalidade. $\mathrm{Na}$ compreensão do princípio de causalidade, não existe nenhum efeito que não tenha uma causa, nenhum movimento que não seja produzido a partir de um móvel, nenhuma ação sem dispêndio de energia. Porém, Del Monte (1991) esclarece que:

\footnotetext{
No campo das 'funções' ou das 'ações' (humanas) do corpo nem sempre se encontram causas 'físicas' cognoscíveis, mensuráveis, definíveis, e, então, a origem deve se encontrada em alguma outra parte 'não conhecida', 'in-consciente' (DEL MONTE, 1991, p. 18).
}

Fazemos, então, as seguintes questões: por que não se enquadram nas respostas do método científico, significa que esses fenômenos não existam? Por que não se enquadram, não poderiam ser estudados? Com e de qual outra forma poderíamos estudá-los? Não haveria aí um problema de método? Não estaríamos tratando de alguns limites do método científico, ou melhor, do paradigma científico no qual estamos ancorados?

Analisando a estrutura das revoluções científicas, Kuhn (2011) suficientemente examinou e sustentou o quanto é difícil modificar (ou mesmo derrubar) os paradigmas de análises e não somente os dados, a sua quantidade ou a sua variedade, mas o nosso modo de sistematizá-los, categorizá-los, em uma palavra, utilizá-los. Para Del Monte, a conclusão a partir desse ponto é: "se o método científico de análise é aquele dominante, eu o utilizarei para qualquer tipo de análise para apoiar as minhas hipóteses e não hipotizarei nem mesmo um outro tipo de método" (1991, p. 18).

Dessa forma, é impossível pensar "fora" do paradigma, da visão, do rigidismo do método. Tudo o que não se enquadra nesse paradigma, eu nem mesmo tento olhar,

\footnotetext{
${ }^{5}$ Nota inserida pela autora.
} 
compreender, verificar, abrir espaço para ouvir, eu simplesmente, descarto ${ }^{6}$ e digo que não é científico. Mas, com qual autoridade põe-se essa forma mentis ${ }^{7}$ e esse modo de agir? Sim, a resposta é, com a autoridade de um critério convencional de fazer ciência e não com a utilização de um critério de natureza - critério convencional que é produzido a partir do consenso daqueles que estão de acordo em um dado momento, tal como apontado por Kuhn (2011):

Homens cuja pesquisa está baseada em paradigmas compartilhados estão comprometidos com as mesmas regras e padrões para a prática científica. Esse comprometimento e o consenso aparente ${ }^{8}$ que produz são pré-requisitos para a ciência normal, isto é, para a gênese e a continuação de uma tradição de pesquisa determinada (KUHN, 2011, p. 30).

Ainda complementa Del Monte (1991):

\begin{abstract}
A discussão entre os estudiosos foi e é focada, sobretudo, sobre a questão metodológica, considerando que aqui estivesse o mérito de uma hipótese, omitindo ou negligenciando os fenômenos que teriam podido fazer pensar a uma realidade diferente daquela vista, partindo da própria realidade e não dos olhos de quem a olhava e, por consequência, a via (DEL MONTE, 1991, p. 18).
\end{abstract}

Assim, não se olha e não se parte, na ciência positivista, da realidade por como, unicamente ou diversamente, ela seja, daquilo que é. Parte-se de teorias, métodos, paradigmas, elucubrações mentais e, inclusive, dados, números, percentuais estatísticos, desvios padrões, médias e tantas outras artimanhas científicas produzidas pelo homem ao longo de uma grande história em nome de dizer o que é científico e o que não é, fundamentado em tantos interesses econômicos, sociais e ideológicos legitimados em nome de um poder que, na grande maioria das vezes, pretende-se sustentar na doxa e não no real em si do mundo-da-vida. Inúmeras vezes, Heisenberg (1996) salientou: “é evidente, mas muito frequentemente esquecido, que a ciência é feita por homens" (p. 7) ${ }^{9}$. Assim:

Influenciado por Bohr, uma das principais preocupações epistemológicas de Heisenberg situa-se na tentativa de dar respostas ao programa de pesquisa que o físico dinamarquês tornou público em 1929, também ele fruto do surgimento da física moderna, em particular da mecânica quântica. Um dos eixos desse programa era a questão: 'Como manter a noção de objetividade se fazemos parte dos processos de observação e mensuração dos fenômenos naturais?'. O ponto de partida para a formulação de uma nova definição de objetividade seria uma frase do próprio Bohr:

\footnotetext{
${ }^{6}$ Porém, temos que verificar, como salienta Kunh (2011), que “...teorias (...) não são em princípio acientíficas simplesmente porque foram descartadas" (p. 21).

${ }^{7}$ Forma mentis é expressão em latim que significa mentalidade.

${ }^{8}$ Itálico inserido pela autora.

${ }^{9} \mathrm{Na}$ citação de Santos (1990): "é o homem que faz a ciência, um facto evidente que é demasiadas vezes esquecido” (HEISENBERG citado por SANTOS, 1990, p. 9). Nota inserida pela autora.
} 
'O homem não é um mero espectador da natureza, mas participa dela ${ }^{10}$, COSTA e VIDEIRA, 2009, p. 11).

Nessa lógica [epistemológica], uma vez que a ciência é feita/produzida por homens e que o homem não é apenas um espectador, mas participa dela, conforme as compreensões ilustres e históricas de Heisenberg e Bohr, na Física, entendemos que a ciência fala o que é a natureza e como ela comporta-se, não de modo unicamente objetivo, mas dependendo da interação que mantemos com ela. A ciência é uma dentre os vários elos da cadeia infinita de contatos que o homem tem com a natureza.

E mais, na ciência normal, de acordo com Kuhn (2011), nem sempre o objetivo da ciência é realmente a descoberta de algo novo, pois "até mesmo o projeto cujo objetivo é a articulação de um paradigma não visa produzir uma novidade inesperada" (p. 58). Neste sentido, geralmente, os cientistas empregam muito tempo em problemas que são considerados "quebra-cabeças", de forma que os resultados a que chegam são significativos não porque portam novidades realmente e descobertas que irão contribuir com resoluções no contexto social, mas porque contribuem para aumentar o alcance e a precisão com os quais o paradigma pode ser aplicado (KUHN, 2011), como aqui também pode ser evidenciado:

Resolver um problema de pesquisa normal é alcançar o antecipado de uma nova
maneira. Isso requer a solução de todo o tipo de complexos quebra-cabeças
instrumentais, conceituais e matemáticos. O indivíduo que é bem sucedido nessa
tarefa prova que é um perito na resolução de quebra-cabeças. O desafio apresentado
pelo quebra-cabeça constitui uma parte importante da motivação do cientista para o
trabalho (...). O critério que estabelece a qualidade de um bom quebra-cabeça nada
tem a ver com o fato de seu resultado ser intrinsecamente interessante ou importante.
Ao contrário, os problemas realmente importantes em geral não são quebra-cabeças
(veja-se o exemplo da cura do câncer ou o estabelecimento de uma paz duradoura),
em grande parte porque talvez não tenham nenhuma solução possível (KUHN, 2011,
p. 59).

Na grande maioria das vezes, busca-se, então, na ciência normal, estar de acordo com o previsto e prescrito, alcançar o antecipado, de modo que, conforme Kuhn, "a ciência normal é uma atividade altamente determinada" (2011, p. 66).

No texto Teorese e Escopo da Ontopsicologia, de 2006, discorrendo sobre as origens da Ontopsicologia, Meneghetti destaca que:

Todos sabem da existência de muitas ciências: a química, a física, a matemática, etc. Para entender como nasce a Ontopsicologia, é preciso partir do fato de que em todo o mundo se fala do homem, da vida, da morte, de Deus. E cada teoria científica

\footnotetext{
${ }^{10}$ A frase original de Niels Bohr é: “...na advertência de que nunca devemos esquecer, em nossa busca de harmonia na vida humana, que, no palco da vida, nós mesmos somos atores e espectadores" (BOHR, 1995, p. 103). Nota inserida pela autora.
} 
aborda a seu modo os vários problemas, tentando dar uma solução. A multiplicidade das ciências nasce da multiplicidade dos problemas aos quais o homem deve responder. Cada setor prepara uma técnica específica para resolver um determinado problema e nasce uma ciência ou disciplina. Por exemplo, a física se propõe a tarefa de explicar o mundo, a religião enfrenta os problemas últimos da natureza humana, a arte é a técnica do belo, a política é a técnica das relações entre as pessoas, ou a economia dos pontos-força entre várias sociedades (MENEGHETTI, 2006, p. 15).

Muitas ciências, segundo o autor, nascem também por necessidade prática de trabalho. Porém, se pergunta: “...mas depois, resolvem o problema humano?” (ibid.). E verifica que “...a Psicologia como ciência nasce da análise do homem, da sua psique, mas a ciência psicológica, no fim, dá a solução ao problema do homem?” (ibid.). O primeiro problema importante/fundamental, ao analisar-se o homem e trabalhar com ele não é o da verdade, mas de realizar a si mesmo (MENEGHETTI, 2006).

Todo homem tem o seu terrível problema, e a exasperação pode ser mais grave naqueles indivíduos que têm mais, porque sofrem em medida maior de carência: por que, se um homem tem tudo - satisfação, dinheiro, amor, primado social - adoece? Apesar do avanço social e científico, o homem continua a estar mal física ou psicologicamente (MENEGHETTI, 2006, p. 15).

Não iremos descrever e apresentar aqui todos os aspectos a respeito do nascimento da Ciência Ontopsicológica ${ }^{11}$, mas um dos pontos importantes a verificar é que a Ontopsicologia nasce justamente após todas as Escolas/Abordagens de Psicologia e diversas áreas das Ciências Humanas, as quais, segundo Meneghetti, não são erradas, porém, “...não realizam o escopo, isto é, são insuficientes para explicar o homem na sua vasta complexidade ${ }^{12 \text {, }}$ (MENEGHETTI, 2006, p. 16).

Dessa forma, o nosso objetivo principal neste artigo é estudar acerca do método ontopsicológico. No entanto, para compreender melhor esse método e suas características, era necessário, primeiramente, essa contextualização acerca das ciências, e principalmente, do Paradigma Positivista nas Ciências.

\subsection{O Método na Ontopsicologia}

Método é uma palavra de origem grega, méthodos, que é composta, etimologicamente, por duas outras palavras: metá e hodós. Metá significa atrás, em seguida, através, e hodós é caminho. Pode ser compreendido, desse modo, como o caminho percorrido para chegar a um

\footnotetext{
${ }^{11}$ Para mais referências verificar Meneghetti (2006) e Meneghetti (2010).

12 Vide também MENEGHETTI, A. Background histórico à ciência ontopsicológica. In: MENEGHETTI, A. Manual de Ontopsicologia. 4. ed. Recanto Maestro: Ontopsicológica Editora Universitária, 2010.
} 
fim. Nas acepções do termo, pelo Dicionário Houaiss da Língua Portuguesa, método é considerado um procedimento, técnica ou meio de fazer alguma coisa, especialmente de acordo com um plano; um processo organizado, lógico e sistemático de pesquisa, instrução, investigação, apresentação; ainda ordem, lógica ou sistema que regula uma determinada atividade e também qualquer procedimento técnico, científico.

A Ontopsicologia é uma ciência que apresenta claramente o seu objeto de estudo, a atividade psíquica; o seu método, a saber, o método bilógico e o seu fim (finalidade) (MENEGHETTI, 2010). O método é bilógico e isso significa que, por duas lógicas, o método caminha, existem duas lógicas de acesso e de estudo, em função, também, e principalmente, das especificidades do objeto de estudo dessa ciência que é a atividade psíquica. Porque, em uma ciência, primeiro, define-se e especifica-se o objeto de estudo, isto é, o que estudar, o que ela estuda, para, a partir da natureza dessa objeto, delimitar e configurar como será o percurso de estudo desse objeto ou como iremos estudar esse objeto - aí, o método. O objeto de estudo da Ontopsicologia, a atividade psíquica é:

\begin{abstract}
A ação-base das modalidades do pensamento e da motivação do existir homem, até a exteriorização somática (o corpo é palavra, o psíquico é sentido). 'Realidade' psíquica (inconsciente, pulsões, associações, transposições oníricas, alucinações, visões, etc.) deve ser entendida com a mesma concretude com a qual um físico concebe a matéria. É um mundo subjetivo operável como: a) intencionalidade em antecipação a qualquer fenomenologia; b) pensamento ou ato já formalizado; c) razão ou vontade consciente; d) via fantasiosa, artística, onírica. A atividade psíquica é sempre invisível. Mesmo o pensamento e a consciência são fenomenologias e não se pode ver a causa em si. Quando pensamos já refletimos: a nossa consciência lê em fenomenologia. O Em Si ôntico é a radicalidade da atividade psíquica, o projeto de natureza que constitui o ser humano. A Ontopsicologia tem por objeto a atividade psíquica inerente à fenomenologia humana, isto é, estuda a experiência psicológica, individua as causas que a constituem e os elementos que podem resolvê-la. A última redução que podemos fazer da atividade psíquica pura não é tanto energia, mas é o processo de formalização. As imagens são estruturas por meio das quais pode ocorrer qualquer variável energética. O princípio age apenas por meio da imagem. Ao dizer 'atividade psíquica', concebe-se o primeiro e fundamental mover-se do homem que, depois, efetua-se como pensamento, emoção, temperamento, caráter, memória, vontade, consciência (...). A atividade psíquica é uma forma que presencia e especifica a ação (MENEGHETTI, 2012, pp. 26-28).
\end{abstract}

Na definição apresentada sobre atividade psíquica, cada palavra pesa, cada palavra tem o seu valor de conteúdo e explicativo, não podemos entender de modo superficial - como geralmente a nossa preguiça mental e ignorância funcionam. Para essa definição, palavra por palavra precisa ser estudada, levando o tempo que for, para que possamos compreender racionalmente e, depois, por evidência, cada aspecto único e uno do conceito. E essa é uma responsabilidade de compreensão individual e em conjunto de todos os estudiosos e 
operadores dessa ciência, de modo completo, integral. E de todos aqueles que querem seriamente e cientificamente compreendê-la.

O autor afirma que "para compreender as dinâmicas e os projetos da vida é preciso ter uma contemporaneidade de diversos conhecimentos" (MENEGHETTI, 2010, p. 129), como veremos no aspecto do método ontopsicológico. O objeto de estudo, a atividade psíquica, é um objeto que possui "...uma fase inconsciente (não perceptível) e uma fase consciente (visível em fenomenologia)". A fase inconsciente diz respeito à ação-base, à(s) imagem(ns), à forma, à potência formalizante, por sua vez, a fase consciente é tudo o que diz respeito aos fenômenos, aos resultados, ao comportamento, à fenomenologia visível, ao resultado das causas, à formalização concreta.

Dessa forma, para compreender a inseidade da atividade psíquica, temos que recorrer a uma racionalidade bilógica: “'Bilógica' significa que são usadas duas lógicas: a) uma lógica intrínseca à estrutura que atua o projeto (...); e b) uma lógica relativa à conjuntura, à variável dos eventos" (MENEGHETTI, 2010, p. 130).

Assim, o método ontopsicológico é "bilógico, processo racional indutivo-dedutivo, com novidade dos princípios complementares do campo semântico, Em Si ôntico, monitor de deflexão" (MENEGHETTI, 2010, p. 131). Dois são os significados para o termo bilógico: a) método indutivo-dedutivo; b) lógica "científica" e lógica "intuitiva". Mesmo dentro de cada uma das lógicas do método bilógico, existem mais dois modos lógicos nos quais proceder, a saber: 1) na parte do método indutivo-dedutivo, encontramos a lógica indutiva e dedutiva; e 2) e na parte do método que usa a lógica "científica" e a lógica "intuitiva", encontramos cada uma das duas como dois modos de proceder da lógica também.

No primeiro aspecto, a parte do método que usa e emprega a lógica do método indutivo-dedutivo, conforme a divisão dos princípios da ciência, partindo de Aristóteles a Tomás de Aquino, a Kant, etc., chegamos ao fato de que existem dois sistemas de conhecimento na racionalidade humana: o indutivo e o dedutivo. No aspecto indutivo, a partir de alguns casos específicos conhecidos, chega-se a formular uma lei geral; do igual de diversos particulares, chega-se a uma unidade de causa. Quando se parte "do particular para o geral", fazemos uma indução. No aspecto dedutivo, partindo de elementos já demonstrados, caso se encontre um fenômeno igual àqueles precedentes estudados, deduz-se que ele responde às mesmas leis. De uma lei geral, chega-se à formulação de uma lei particular implícita nela. Quando se parte do "geral para o particular", fazemos dedução (MENEGHETTI, 2010; EINSTEIN, 1919/2005; FERRARA, 1987; NASCIMENTO, 1998). 
$\mathrm{Na}$ Filosofia, mais especificamente na Lógica, assim como na Física, indução e dedução são formas de raciocínio. Na indução, o raciocínio parte de elementos particulares até chegar em uma conclusão. Na dedução, o raciocínio parte da conclusão para chegar aos elementos particulares. Na Física, por exemplo, em 1919, Albert Einstein (2005) escreveu um breve ensaio intitulado "Indução e Dedução na Física", discutindo o método indutivo, dedutivo e também apontando um especial papel da intuição na produção do conhecimento e das descobertas científicas, sendo que, para ele, a compreensão intuitiva dos aspectos essenciais é fundamental no enorme complexo de fatos que leva o pesquisador a construir uma ou várias leis fundamentais hipotéticas que, depois, serão trabalhadas pela indução e dedução. Para Einstein, na obra de 1919, a escolha intuitiva e a visão intuitiva (termos do próprio autor) do pesquisador são fundamentais para a ciência.

No segundo modo de proceder e empregar a lógica, usamos a lógica "científica" e a lógica "intuitiva". A lógica científica foi desenvolvida por meio de séculos de pesquisa, tradições, experiências da Filosofia, Psicologia, História e tantas outras áreas. "É tudo aquilo que, em qualquer contexto histórico, já é acreditado e estabelecido por uma academia, por uma universidade, por uma cultura, etc.” (ibid.). Mas, junto disso, "a Ontopsicologia parte do princípio de que para compreender o homem é preciso usar todo o homem" (ibid.). Neste sentido, temos a lógica científica que nos descreve e explica tantas questões e conhecimentos importantes acerca do homem, mas também a lógica intuitiva, que, muitas vezes, refere-se a tudo o que não é reconhecido (ainda) pela ciência tradicional. Eis que o autor apresenta, em síntese, o método bilógico:

Retornando ao método bilógico, o ontopsicólogo ${ }^{13}$, para poder conhecer o homem, usa a intuição e o raciocínio indutivo-dedutivo, ou seja, une o conhecimento do campo semântico à lógica da razão. Não se trata de excluir a razão, mas de acrescentar o critério organísmico (MENEGHETTI, 2010, p. 133).

A lógica da razão é dada pelo processo da lógica racional indutivo-dedutiva, unindo-se a esta e acrescentando a lógica intuitiva, dada pela análise cruzada do conhecimento e aplicação das três descobertas ${ }^{14}$ da Ontopsicologia - campo semântico, Em Si ôntico, monitor de deflexão. Não se exclui a razão, mas se lhe acrescenta o critério organísmico. Neste sentido, o critério organísmico é parte essencial do método ontopsicológico, que deve ser

\footnotetext{
${ }^{13}$ Técnico operador de Ontopsicologia.

${ }^{14}$ Para conhecimento inicial e aprofundado a respeito das três descobertas da Ontopsicologia, vide as obras Manual de Ontopsicologia (2010), Campo Semântico (2015b), Em Si do homem (2015c), Monitor de Deflexão (2017), de autoria de Antonio Meneghetti, Ontopsicológica Editora Universitária. Para utilizar e empregar o método ontopsicológico é fundamental o conhecimento, por parte do operador, científico-técnico-racional e também existencial e empírico das três descobertas da Ontopsicologia.
} 
conhecido, aprendido e praticado em um training de autenticação por parte do operador de Ontopsicologia, para poder aplicar o método ontopsicológico com exatidão e precisão ${ }^{15}$. O critério organísmico é um:

\begin{abstract}
Complexo de ações e reações determinadas pelo conjunto orgânico-corpóreo: em particular, o cérebro visceral, sistema cardíaco e pulmonar, estômago e funções sexuais e eróticas. O critério organísmico é vetor da emocionalidade com ausência de interferências cerebrais, ideológicas. É a exclusão de qualquer imagem, síntese ou programa definido como memética. Atualidade intuitiva, vivida em flash formal sem tempo e repetição (...). O cérebro viscerotônico é a primeira fenomenologia mais física e emocional do $\mathrm{Em} \mathrm{Si}$. Ele reage em antecipação a qualquer forma de conhecimento de que somos dotados. É a direta fenomenologia que o corpo expõe como significado da posição ou presença do Em Si ôntico (MENEGHETTI, 2012, pp. 70-71).
\end{abstract}

É a percepção organísmica que permitirá a compreensão da atualidade intuitiva, porém, obviamente, junto da exatidão de consciência do operador (um é premissa para o outro e um é também, ao mesmo tempo, resultado do outro). A percepção organísmica, por meio do complexo de ações e reações determinadas pelo conjunto orgânico-corpóreo, especialmente em toda a região do cérebro visceral (viscerotônico), que envolve o sistema cardíaco, pulmonar, estômago, intestinos e funções sexuais, dá-nos o impacto da informação real e intuitiva no aqui-agora, em cada momento e situação vividos. "A primeira fase de conhecimento é visceral e permanece primária por todo o arco da existência. O primeiro estado de reação do corpo humano é conhecimento na fase visceral, que responde com imediatismo de instinto; depois, o conhecimento formal se distribui" (MENEGHETTI, 2015b, p. 100).

A partir da percepção organísmica, essa percepção exata, é a consciência que deve ter a capacidade de compreensão racional fazendo uma leitura exata da realidade. Nesse ponto, a consciência deve ser um instrumento de leitura e compreensão transparente da realidade, sem operar o desvio/distorção/deflexão da informação por meio das lógicas meméticas, complexuais e do monitor de deflexão. Ter a capacidade de leitura com exatidão da informação é, ao mesmo tempo, premissa para a aplicação do método ontopsicológico e também um resultado da aplicação do método ontopsicológico. Fundamental, constante e cotidianamente, nesse processo para o operador desse conhecimento é fazer a revisão crítica da consciência, como, por exemplo, por meio da consultoria de autenticação.

\footnotetext{
${ }^{15}$ Training onde três pontos são fundamentais de serem vivenciados por parte do operador: o estilo de vida, a metanoia e o estudo da Ontopsicologia.
} 
Cabe, nesse ponto, verificar também o que é a intuição, já que uma das lógicas do método bilógico da Ontopsicologia é a lógica intuitiva. Intuição, com origem etimológica no latim, intus actionis, significa dentro ou íntimo da ação. Intuição é:

\begin{abstract}
Saber o íntimo da ação. Ver o fazer. Conhecer os modos ou estruturas interiores de um projeto de ação ou evento. Colher as coordenadas de uma gestalt. Saber antes dos efeitos. Formalização do Eu a priori em relação a. Posição de ótima funcionalidade por parte do $\mathrm{Em} \mathrm{Si}$ ôntico em relação a um projeto ou evento (MENEGHETTI, 2012, p. 144).
\end{abstract}

Intuição é a informação do Em Si ôntico em ato, em uma imagem, em um flash, em uma gestalt completa, como uma evidência, saber e ver o fazer no íntimo da ação. Na Escola Ontopsicológica, a compreensão de intuição não tem nada a ver com tudo o que se diz no senso comum a respeito de intuição ou com os saberes correntes a respeito. A partir do momento em que o Em Si ôntico já faz parte do Ser e é coligado ao íntimo da vida, se sabe antes e sabe-se por evidência, qual é a solução otimal em cada necessidade, momento, exigência, tarefa que o Eu lógico-histórico tenha, justamente esse ponto: “...posição de ótima funcionalidade por parte do Em Si ôntico em relação a um projeto ou evento" (ibid.). É necessário que o sujeito tenha uma consciência exata que saiba ler e colher essa informação. A intuição também é compreendida neste aspecto: “eu, sujeito, sou no objeto e o objeto é em mim no momento do uno. Esse é o ponto nevrálgico de toda a intuição" (MENEGHETTI, 2007, p. 51). Nesse ponto, no método bilógico, o autor segue explicando que:

\begin{abstract}
O ontopsicólogo, na sua análise, parte da intuição conduzida através da leitura das seis linguagens diagnósticas ${ }^{16}$, com as quais faz uma diagnose completa (indução); sucessivamente demonstra fenomenicamente a intuição (dedução). A intuição é a semântica unidirecional do $\mathrm{Em} \mathrm{Si}$, em antecipação ao monitor de deflexão, aos complexos, aos estereótipos culturais e logísticos da sociedade. A indução é a pesquisa dos elementos para chegar à exatidão. A dedução é a partida de elementos já demonstrados (MENEGHETTI, 2010, p. 133).
\end{abstract}

Formalizamos, aqui, em um gráfico, uma possível imagem para a verificação toda, junta dos dois modos de proceder da lógica no método ontopsicológico:

Gráfico 1: Aplicação do Método Bilógico considerando um momento de contato na relação entre consultor ontopsicólogo e cliente, por exemplo (a intuição é a informação que o consultor tem do cliente no momento do impacto inicial)

\footnotetext{
${ }^{16}$ Anamnese linguística e biografia histórica, análise do sintoma ou problema, fisiognômica-cinésica-proxêmica, sonho, campo semântico, resultado. Essas seis linguagens são os instrumentos de análise/diagnose da Ontopsicologia que integram, de modo especial, o método ontopsicológico [nota inserida pela autora].
} 


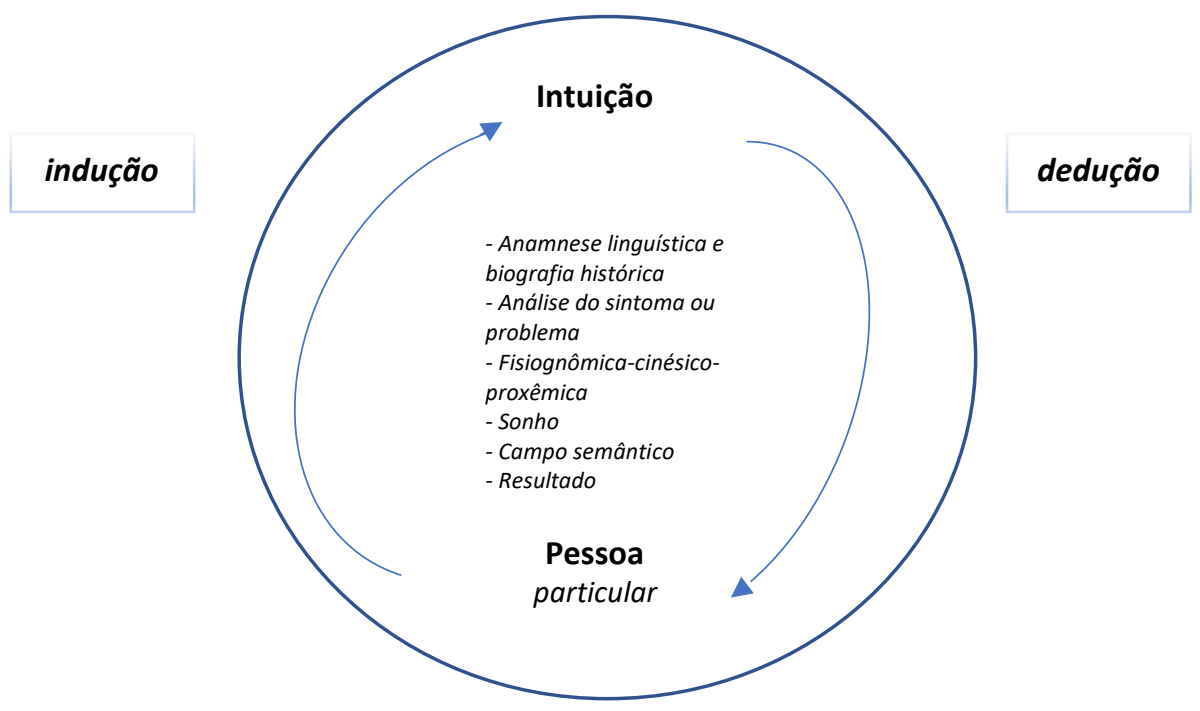

Fonte: imagem elaborada neste estudo a partir da explicação de Meneghetti (2010).

Considerando a imagem anterior, o consultor, no momento do impacto inicial com o cliente, tem uma intuição (a partir de sua percepção organísmica utilizando o campo semântico - lógica intuitiva). Em sua análise, ele parte da intuição conduzida através da leitura das seis linguagens diagnósticas, com as quais faz uma diagnose completa (momento da indução, lógica racional indutiva) e, a partir disso, sucessivamente, demonstra fenomenicamente a intuição (momento da dedução, lógica racional dedutiva). A indução é a pesquisa dos elementos para chegar à exatidão, porém, já a partir do momento da percepção da intuição. A dedução é a partida de elementos já demonstrados - a saber, as informações a partir do uso das seis linguagens diagnósticas apresentadas - para confirmar a informação primeira, obtida por meio da intuição. A partir da intuição, inicia-se o processo indutivo e fazse uma diagnose completa. Na sequência, evidenciada a fenomênica da intuição, procede-se ao processo dedutivo. Tentamos separar para explicar e compreender, porém, esse processo e aplicação do método bilógico dá-se de modo amalgamado, é todo junto.

\footnotetext{
Uma vez colhida a realidade por meio da percepção visceral, que indica biologicamente a situação, é preciso fazer um compromisso histórico, sincronizando aquele conhecimento com as ordens da racionalidade social. É preciso usar ambos os conhecimentos, aproximar-se do real de modo bilógico; a natureza dá a informação sobre a exatidão da situação, depois o sujeito deve impostar uma estratégia de modo racional, porque o homem é também histórico (MENEGHETTI, 2015b, p. 100).
}

Essa última parte da citação é uma síntese da aplicação do método bilógico: é preciso usar ambos os conhecimentos, aproximar-se do real de modo bilógico, pois, a natureza dá a informação sobre a exatidão da situação, depois o sujeito deve impostar uma estratégia de modo racional, porque o homem é também histórico. A partícula "bi(s)-", de "bilógico", 
provém do advérbio latino bis que significa duas vezes ${ }^{17}$. No método bilógico, então, a lógica “caminha" duas vezes, ou podemos dizer de duas formas a lógica "caminha"/“é aplicada": do modo racional indutivo-dedutivo e do modo intuitivo, uma identificando a outra e uma reforçando a outra. É, de fato, uma revolução de paradigma científico para enriquecer o processo perceptivo-cognitivo metodológico do conhecer humano, que não deixa de usar a lógica do paradigma positivista (a razão, a racionalidade), ao contrário, enrique-o, pois, à lógica da razão é acrescentada a lógica intuitiva, dada pela análise cruzada com novidade dos princípios complementares de campo semântico, Em Si ôntico, monitor de deflexão. No entanto, a tarefa fundamental “...é aquela de recuperar a integridade de consciência sobre a informação organísmica, de outro modo a ciência é impossível. O erro está sempre na consciência porque não reflete bem como as coisas estão para o sujeito" (MENEGHETTI, 2014, p. 13). Por isso, o método da Ciência Ontopsicológica propõe, continuamente, a necessidade da revisão crítica da consciência para refundá-la sobre bases ontológicas.

\begin{abstract}
Uma vez que o ontopsicólogo ${ }^{18}$ tem a intuição da situação do cliente (através da comparação do que é evidenciado pelo campo semântico), procede através da indução, fazendo algumas provas ('vejamos se isto... etc.'). No final demonstra a causa ao sujeito, através da dedução ('Portanto, é assim... verificado isso... está mal porque quando menino teve isso') (...). Contata-se o cliente através da percepção do campo semântico. Depois do impacto com ele, faz-se a análise da sua situação, unindo - à análise efetuada através da percepção do campo semântico - a análise efetuada pela leitura das outras quatro linguagens (anamnese, problema ou sintoma, cinésico-proxêmica, sonho): evidencia-se o estado do cliente, o complexo, e intercepta-se o fim primário. Para curar, não basta fazer o levantamento da causa da patologia ou do problema do cliente, mas - além disso - é preciso encontrar a pulsão do Em Si ôntico em situação. Isso consente uniformar o Eu lógico-histórico do sujeito à sua intencionalidade de natureza. Através da leitura do campo semântico, é possível evidenciar tanto a pulsão do complexo (que não permite realizar a unidade de ação de modo funcional), quanto o que o Em Si indica (MENEGHETTI, 2010, pp. 133-134).
\end{abstract}

Com a aplicação do método ontopsicológico, em uma situação de consultoria de autenticação $^{19}$, por exemplo, de acordo com as explicações apresentadas até então, acerca da metódica bilógica, é possível evidenciar o estado do cliente de modo integral, verificar a informação/intencionalidade do complexo dominante e interceptar/apreender a finalidade primeira dessa pessoa, a informação/intencionalidade do Em Si ôntico. Nesse ponto, o primeiro aspecto da demonstração do método ontopsicológico é o desaparecimento do problema ou do sintoma. Para, de fato, resolver o ponto inicial é fazer o levantamento da

\footnotetext{
${ }^{17}$ Dicionário Houaiss da Língua Portuguesa, versão eletrônica.

${ }^{18}$ Profissional técnico que aplica o método da Ciência Ontopsicológica [nota inserida pela autora].

${ }^{19}$ Para conhecimento, verificar os instrumentos de intervenção da Escola Ontopsicológica, na Parte II do livro Manual de Ontopsicologia, p. 281-330 (MENEGHETTI, 2010).
} 
causa da patologia ou do problema do cliente e evidenciar essa informação para ele. Para que ocorra a resolução dessa situação é responsabilidade do cliente decidir o que fará com essa informação, pois a partir do momento em que sabe, uma ação importante seria fazer a mudança. Porém, a decisão e escolha são sempre do cliente.

Vidor (2013) ratifica essa explicação salientando que, para que o eu consciente esteja em coincidência com os valores da própria vida, inerentes à natureza, a Ontopsicologia propõe o método indutivo-dedutivo e intuitivo.

Como bem evidenciado por Meneghetti (2010), “...para curar não basta fazer o levantamento da causa da patologia ou do problema do cliente, mas - além disso - é preciso encontrar a pulsão ${ }^{20}$ do Em Si ôntico em situação, compreendê-la e realizá-la e atuá-la no contexto histórico-social, sendo essa uma tarefa do Eu lógico-histórico a cada momento. Caso assim seja feito, essa passagem consente uniformar o Eu lógico-histórico do sujeito à sua intencionalidade de natureza naquele momento e produzir autóctise histórica.

No aspecto da lógica intuitiva, com a aplicação cruzada das três descobertas da Ontopsicologia, como apresentado pelo autor, por meio da leitura do campo semântico é possível evidenciar a pulsão do complexo (que não permite realizar a unidade de ação de modo funcional), quanto a informação do Em Si ôntico (MENEGHETTI, 2010), sendo esses dois pontos/momentos de total importância na aplicação do método ontopsicológico. É necessário retomar a norma de sanidade em um primeiro momento, mas não somente isso, para a realização, de fato, do sujeito, é preciso, continuamente, seguir e realizar a pulsão do Em Si ôntico momento a momento. Esse ponto fica claro em Meneghetti (2014), quando aborda que é necessário que se identifique a informação do Em Si ôntico em cada sujeito e que se trabalhe para a evolução e atuação dessa informação no contexto histórico:

\begin{abstract}
Identificar o Em Si ôntico e começar a autenticação do sujeito, ou seja, reportar o sujeito da dispersão produzida pela mêmica societária à virtualidade da própria intencionalidade de natureza (autêntico significa ser igual a como o ser nos põe). Uma vez individuado o projeto originário, o Em Si ôntico daquele sujeito, como se pode educá-lo? É preciso saber individuar quais são as passagens práticas, existenciais para a evolução do Em Si ôntico na práxis existencial (MENEGHETTI, 2014, pp. 15-16).
\end{abstract}

Aí tratamos do processo de evolução em criatividade do sujeito. Mas não de uma mera criatividade como pode ser conhecida no senso comum, pois a finalidade "...da existência humana é a criatividade. O ser humano não é feito para repetir, mas para evoluir"

\footnotetext{
${ }^{20}$ Pulsão, em Psicanálise, é entendido como um "processo dinâmico, força ou pressão, que faz o organismo tender para uma meta, a qual suprime o estado de tensão ou excitação corporal que é a fonte do processo" (HOUAISS, versão eletrônica).
} 
(MENEGHETTI, 2010, p. 230). Na lógica da finalidade da existência humana em criatividade, constantemente a pessoa deve subjetivar o objeto, metabolizar o objeto, de acordo com a solução otimal do próprio Em Si ôntico em ato histórico, para transformar o mundo como próprio Eu (ibid.).

Ser criativo, neste sentido, significa saber dar/encontrar respostas novas, específicas para os problemas e as necessidades que se apresentam - que, muitas vezes, até são semelhantes, mas que exigem novidades e inovação de solução. Dessa forma, considerando o método bilógico e a premissa de ser uma ciência interdisciplinar, a Ontopsicologia é, de fato, “...um método para autenticar e desenvolver o homem criativo, mas para obter isso é preciso saber ler o princípio elementar que constitui a natureza humana e criteriar o positivo e negativo para ela" (MENEGHETTI, 2014, p. 13).

Um dos aspectos fundamentais da lógica da interdisciplinaridade, de acordo com Nicolescu (1999), é justamente este: a interdisciplinaridade diz respeito à transferência de métodos de uma disciplina para outra. Neste sentido, também a Ontopsicologia é interdisciplinar, pois o seu método pode ser utilizado/aplicado no interior de outras disciplinas. Nicolescu (1999) afirma que a interdisciplinaridade possui três graus: a) um grau de aplicação, no qual, por exemplo, os métodos da Física Nuclear transferidos para a Medicina levam ao aparecimento de novos tratamentos para o câncer; b) um grau epistemológico, no qual a transferência de métodos da Lógica formal para o Direito produz análises interessantes na epistemologia do Direito, por exemplo; c) um grau de geração de novas disciplinas, em que a transferência dos métodos da Matemática para os fenômenos meteorológicos ou para os da bolsa de valores origina a teoria do caos ${ }^{21}$, por sua vez.

O método bilógico ontopsicológico tem como finalidade conhecer as causas primeiras, por esse motivo também que uma das principais definições da Ciência Ontopsicológica é configurada da seguinte forma: “...estudo dos comportamentos psíquicos em primeira atualidade, não excluída a compreensão do ser” (MENEGHETTI, 2010, p. 19). Nessa definição, a expressão “em primeira atualidade” significa, justamente, estudar a atividade psíquica (objeto de estudo da Ontopsicologia), enquanto está agindo, pois a psique humana continuamente age e colhê-la/compreendê-la em causa, conhecer a e na causa. Considerando a lógica da interdisciplinaridade apresentada anteriormente, é também neste sentido que o método biológico valida a Ontopsicologia como uma ciência interdisciplinar, pois em todas as áreas do conhecimento é fundamental conhecer as causas dos fenômenos para poder direcionar-se os resultados em prol da eficiência humana e do conhecimento científico.

\footnotetext{
${ }^{21}$ Nicolescu (1999) citado por Ribeiro (2019).
} 
Para a formação do profissional técnico que irá utilizar esse método, portanto, são necessárias três preparações, tendo em vista a possibilidade de conhecer em antecipação as causas por meio de um método que permite ao ser humano e as suas fenomenologias resultados de funcionalidade e evolução. Meneghetti (2010) salienta essas preparações da seguinte forma:

\begin{abstract}
A metodologia se expõe principalmente sobre três preparações por parte do operador: a) bagagem de conhecimentos sobre a teoria ontopsicológica; b) autenticidade da pessoa (o operador deve ser exato, portanto, deve fazer metanoia, $\mathrm{e}$ isso significa distanciar-se da fixidez dos estereótipos sociais, não ser mais ator do sistema e ter uma lógica exata); c) conhecimento do campo semântico. O campo semântico é válido somente na pessoa que tem a bagagem cognoscitiva da Ontopsicologia e fez metanoia. Esses três aspectos devem estar presentes sempre continuamente (MENEGHETTI, 2010, p. 134).
\end{abstract}

Esses são, portanto, três aspectos de preparação que devem estar continuamente presentes no operador que deseja aplicar o método ontopsicológico: a bagagem de conhecimentos teóricos ontopsicológicos como estudo técnico, racional, científico; a autenticidade da pessoa - com ênfase para o aspecto da metanoia, do distanciar-se da fixidez dos estereótipos sociais e do sistema, desenvolvendo uma exatidão de consciência - aspecto de formação existencial; e conhecimento sobre o campo semântico - que se torna, ao mesmo tempo, premissa, em uma dinâmica dialética, para a pessoa que tem bagagem de conhecimento cognoscitivo-teórico da Ontopsicologia e que faz, continuamente, metanoia.

\title{
2.3 O Método Ontopsicológico e o Nexo Ontológico
}

O método ontopsicológico com a possibilidade de conhecer as causas primeiras requer uma racionalidade bilógica. Como visto anteriormente, o termo 'bilógico' no sentido aplica-se no sentido que “...significa que são usadas duas lógicas: a) uma lógica intrínseca à estrutura que atua o projeto (...); e b) uma lógica relativa à conjuntura, à variável dos eventos" (MENEGHETTI, 2010, p. 130). A primeira lógica é a lógica intuitiva e a segunda lógica, a lógica racional indutiva-dedutiva.

$\mathrm{Na}$ exposição, explicação e orientações acerca da implementação do Curso de Bacharelado em Ontopsicologia, realizada em parte de uma das conferências proferidas pelo Acadêmico Professor Antonio Meneghetti no dia 14 de outubro de 2012, por ocasião de um residence ontopsicológico, no Centro Ecobiológico de Lizari, próximo à Riga, capital da 
Letônia, Meneghetti finalizou aquela parte da conferência com uma intervenção prática que será aqui relatada/narrada na seguinte cena ${ }^{22}$ :

Está situado em pé na sala de conferências, em frente à mesa desta sala e a todo o público ali presente, colocando-se no papel de um cientista, pesquisador, como se estivesse falando de si mesmo, com a mão direita apoiada no centro de seu peito e a mão esquerda no bolso do colete, verbaliza:

'Eu, grande cientista, grande médico, grande sociólogo, grande pedagogo, grande, etc., etc., etc. ...'

Ao terminar de verbalizar esta frase, caminha, deslocando-se do lado esquerdo para o direito na frente da sala, na frente e ao chegar próximo a um rapaz que está sentado em um banco alto olhando para ele, direciona-se olhando para as costas do rapaz, toca-as com a mão direita fechada como se 'batendo' ${ }^{23} \mathrm{com}$ a ponta dos dedos da mão direita, em um ponto dessas costas. Neste momento, o rapaz, que está sentado olhando-o para ele, faz um movimento de deixar as costas eretas e continua olhando a ele. Em seguida, Meneghetti, das costas, estando de lado ao rapaz, toca em seu braço esquerdo retirando sua mão da perna esquerda. Meneghetti está um pouco encurvado agora e toca, mantendo o mesmo formato da mão direita o joelho esquerdo do rapaz, e olha para o joelho, enquanto o rapaz continua olhando para ele e sorri. Na sequência, Meneghetti afasta-se levemente da direção do rapaz como se fosse olhar para ele um pouco mais de longe, deixa suas costas eretas, olha de frente para o rapaz e levanta levemente suas duas sobrancelhas como se estivesse observando algo com maior curiosidade. Imediatamente, aproxima-se do rapaz e com suas duas mãos toca os olhos do rapaz (que rapidamente os fecha), como se estivesse examinando os olhos dele, afasta-se novamente para olhar de uma posição um pouco mais distante e coloca sua mão esquerda sobre seu queixo, em uma posição de indagação. Logo, caminha girando até atrás do rapaz, na lateral e levanta uma ponta de seu casaco, e o rapaz sorri e olha para trás para ver o que está fazendo. Meneghetti retorna para a frente e levanta o braço esquerdo do rapaz, que estava apoiado na perna do próprio rapaz e segura e observa os dedos da mão esquerda do rapaz, enquanto o rapaz acompanha com o olhar e em silêncio todos estes movimentos de observação, ele larga de leve o braço e a mão esquerda sobre a perna para continuar apoiado. Então, Meneghetti afasta-se novamente do rapaz e cruza os braços, observando com posição de indagação, enquanto apoia novamente sua mão esquerda sobre seu queixo (de Meneghetti), aproxima-se do rapaz, colocando levemente sua mão sobre o ombro esquerdo, estando lado a lado com o rapaz, olhando em seus olhos e diz (chama seu nome):

\section{- Igor?!}

Enquanto o rapaz, olhando para Meneghetti, faz um sinal de, rapidamente, levantar e abaixar sua cabeça, como que respondendo fisiognomicamente ao chamado de seu nome por Meneghetti. Na sequência, Meneghetti dirige-se ao público presente e diz:

- Toda a ciência faz aquilo que eu fazia: indaga o objeto permanecendo estranha a ele. Com a percepção semântica [e neste momento Meneghetti faz um gesto com sua mão direita de ida e volta em relação ao seu viscerotônico e do rapaz], sei que é um como eu. Sei que é Igor, depois eu posso fazer a aplicação médica, se está mal, se tem uma doença nas pontas do cabelo, sei lá. Mas, com o nexo ontológico, eu tenho a primeira causa, a primeira entidade, a primeira identidade do objetivo de pesquisa, a primeira identidade do objeto de pesquisa. Isto é, é o conhecimento que a natureza usa consigo mesma, que o universo usa consigo mesmo, e é igual ${ }^{24}$.

Na cena aqui narrada, encontramos uma brevíssima apresentação do que vem a ser a aplicação em ato do método bilógico. Isto é, processo de investigação/pesquisa e processo de

\footnotetext{
${ }^{22} \mathrm{Na}$ narrativa que ora se segue, as palavras escritas com letra em posição normal, apenas com tamanho menor, 10 , referem-se à descrição feita pela autora deste artigo a partir da visualização, diversas vezes, das imagens gravadas em vídeo do momento em questão. As palavras escritas em itálico e entre aspas referem-se ao conteúdo/informação verbal que foi proferida pelo Acadêmico Professor Antonio Meneghetti na cena relatada/narrada.

${ }^{23}$ Com a mão direita fechada como se faz ao bater em uma porta.

${ }^{24}$ Informação verbal de conferência proferida por Meneghetti no Residence Nostalgia-Lizari realizado no Centro Ecobiológico de Lizari, dias 12 a 14 de outubro de 2012, próximo à Riga, Letônia.
} 
conhecimento racional indutivo-dedutivo, com observação de acordo com o método científico galileano, com a novidade dos princípios complementares de campo semântico, Em Si ôntico, monitor de deflexão, que permitem configurar a lógica intuitiva, tendo a aplicação de ambas as lógicas continuamente confrontadas e complementares uma a outra.

De modo geral, toda a nossa ciência positivista faz isso: "indaga o objeto permanecendo estranha a ele”, o que configura um modo de conhecer, que não é errado, mas que possui uma especificação metodológica que é justamente conhecer de modo neutro, sem envolvimento subjetivo, conhecer de modo externo, fazendo observação conforme descrita por esse método, conhecer de modo objetivo, racional, como apresentado no início deste estudo e como visto em Khun (2011), ao advertir a necessidade de um método a partir do qual olhar não somente o que é externo (o que está fora de nós), mas também aquilo que é interno. Ora, essa proposta de modo de conhecer produzirá um tipo de conhecimento com um certo limite, como expresso, não errado, mas incompleto, ou seja, se conhecem os efeitos, os fenômenos, “o depois”, os comportamentos, aquilo que é visto/objetivo, com esse método.

A complementaridade com o conhecimento resultante da aplicação do segundo modo da lógica, como proposto pelo método ontopsicológico, isto é, retomando o uso contemporâneo das três descobertas da Ontopsicologia, permite evidenciar o porquê, as causas, o nexo ontológico. Como expresso pelo autor, “...com o nexo ontológico eu tenho a primeira causa, a primeira entidade, a primeira identidade do objeto de pesquisa...".

A lógica intuitiva, do método bilógico, com a análise cruzada propiciada pela informação resultante da aplicação das três descobertas da Ontopsicologia dá a possibilidade de conhecer "de dentro" do próprio sujeito do conhecimento, a causa. E esse é um dos pontos sobre porque o método da Ontopsicologia pode ser usado/aplicado no interior de todas as demais ciências, intensificando a interdisciplinaridade, pois retoma a comunicação do campo semântico, a comunicação e a informação que a vida usa no interior das próprias individuações.

\section{Considerações Finais}

Do quanto aqui visto e estudado, a Ciência Positivista não tem a conexão, o link, o contato, de fato, com o real em si, com a causa, com o conhecer a partir de dentro do sujeito, com exatidão de consciências, as causas que não são explicadas de modo externo. Em complementaridade, a Ciência Ontopsicológica dá essa solução em relação à causalidade primeira da vida, das coisas, das situações, dos efeitos que operam dentro do homem, da vida, 
da sociedade. Todas as disciplinas aprendem estereótipos e, depois, para conhecer o objeto de pesquisa fazem-no por meio destes estereótipos. Mas o problema existe sempre, persiste. Dão o mundo por pressuposto, a nossa consciência dá o mundo por pressuposto - operamos, assim, a partir da Ciência Positivista, que nos ensina a olhar o mundo e a considerar o mundo de modo objetivo (objetivista) e autônomo, mas, enquanto isso, perdemos o mundo-da-vida ${ }^{25}$. $\mathrm{Na}$ Ciência Positivista, toda pesquisa é somente feita com o $\mathrm{Eu}$, a partir do $\mathrm{Eu}$, com a consciência, um Eu formado pela sociedade, no entanto, é um Eu que não é autêntico, pois a sua consciência, na grande maioria das vezes, não possui reversibilidade com o real.

Dessa forma, a nossa ciência está fora, perdeu a causalidade real. É necessário um outro tipo de análise sobre as informações que são já ativas na natureza intrínseca entre o homem e o objeto de pesquisa. A Ontopsicologia está de acordo com os conhecimentos técnicos. Mas diz, confirma, demonstra que há um link a priori entre o operador e o objeto de pesquisa - esse link é baseado sobre a semântica, a intuição do Em Si ôntico, que diz em relação a qualquer situação se é própria ou não é própria, funcional ou não, se é dentro ou fora, qual o modo de conveniência para o sujeito. Existe sempre, imediatamente, uma resposta organísmica do sujeito. O ser do objeto e o ser do sujeito são símiles, são iguais e, portanto, dá-se o conhecimento. E isso é possível com a aplicação do método bilógico da Ontopsicologia.

O nexo ontológico "é a passagem em que o meu pensamento coincide com o mundoda-vida" (MENEGHETTI, 2002/2010, p. 503). Nexo ontológico é, então, reencontrar o ponto de contato, o ponto de encontro, entre o Eu lógico-histórico e Em Si ôntico, para produzir a evidência do conhecimento exato, no sentido de conhecimento que possui a reversibilidade com o real, com o mundo-da-vida. "A Ontopsicologia se preocupa sempre com o nexus: a lógica do homem, o seu conteudismo é adequado ao real?” (MENEGHETTI, 2009a, p. 61). A ciência exata deve ter sempre ativo e definido o modo que age, o nexus com o real externo, com o real material concreto. Qualquer situação humana pode ser resolvida a partir do momento que o operador conhece o nexus científico, porque a realidade responde a ele e isso é sempre demonstrado pelos resultados. Portanto, a cognição exata é aquela que tem a capacidade ao nexus, à conexão, à interação, à reversibilidade, evidências que o método ontopsicológico consente ao operador técnico que possui continuamente as três preparações aqui apresentadas.

\footnotetext{
${ }^{25}$ Husserl (1961).
} 


\section{Referências}

BOHR, N. Física atômica e conhecimento humano. Ensaios 1932-1957. Rio de Janeiro: Contraponto, 1995.

COSTA, F. A. da; VIDEIRA, A. A. Apresentação ao Manuscrito de 1942. p. 7-38. In: HEISENBERG, W. K. A ordenação da realidade (1942). Rio de Janeiro: Forense Universitária, 2009.

DEL MONTE, E. S. Psiche, soma, monitor di deflessione. L'ipotesi di campo in ontopsicologia e in fisica. Nuova Ontopsicologia, n. 3, p. 15-28, Roma, 1991.

EINSTEIN, A. Indução e dedução na Física (1919). Scientiae Studia, São Paulo, v. 3, n. 1, p. 663-664, 2005.

FERRARA, L. A ciência do olhar atento. Trans/Form/Ação, São Paulo, v. 9, n. 10, p. 1-7, 1987.

FREUD, S. O Delírio e os Sonhos na Gradiva, Análise da Fobia de um Garoto de Cinco Anos e Outros Textos. Obras Completas. V. 8. São Paulo: Companhia das Letras, 2015.

HEISENBERG, W. K. A parte e o todo. Encontros e conversas sobre física, filosofia, religião e política. Rio de Janeiro: Contraponto, 2996.

HEISENBERG, W. K. Fisica e Filosofia. Milano: Il Saggiatore, 2003.

HEISENBERG, W. K. A ordenação da realidade (1942). Rio de Janeiro: Forense Universitária, 2009.

HEISENBERG, W. K. Le manuscrite de 1942. Paris: Éditions Allia, 2010.

HEISENBERG, W. K. Quantentheorie und Philosophie. Stuttgart: Reclam, 2015a.

HEISENBERG, W. K. Mutamenti nelle basi della scienza. Torino: Bollati Boringhieri, 2015b.

HOUAISS, A. Dicionário eletrônico Houaiss da Língua Portuguesa. Versão 2.0.1.

HUSSERL, E. La crisi delle scienze europee e la fenomenologia trascendentale. Per un sapere umanistico. Milano: Il Saggiatore, 1961.

KANT, I. Critica della ragion pura. Bari: Laterza, 1979.

KUHN, T. A estrutura das revoluções científicas. 10. ed. São Paulo: Perspectiva, 2011.

MENEGHETTI, A. O nexo ontológico na fenomenologia das ciências. p. 499-509. In: MENEGHETTI, A. Manual de Ontopsicologia. 4. ed. Recanto Maestro: Ontopsicológica Editora Universitária, 2002/2010.

MENEGHETTI, A. Nova Fronda Virescit. Introdução à Ontopsicologia para jovens. Vol. 1. Recanto Maestro: Ontopsicologica Editrice, 2006. 
MENEGHETTI, A. Campo Semântico: individuação e estratégia. Interferência sobre o operador. p. 49-61. In: MENEGHETTI, A. Atos do Congresso Business Intuition 2004. São Paulo: FOIL, 2007.

MENEGHETTI, A. Dalla coscienza all'Essere. Come impostare la filosofia del futuro. Roma: Psicologica Editrice, 2009.

MENEGHETTI, A. Manual de Ontopsicologia. 4. ed. Recanto Maestro: Ontopsicológica Editora Universitária, 2010.

MENEGHETTI, A. Dicionário de Ontopsicologia. 2. ed. Recanto Maestro: Ontopsicológica Editora Universitária, 2012.

MENEGHETTI, A. Pedagogia Ontopsicológica. 3. ed. Recanto Maestro: Ontopsicológica Editora Universitária, 2014.

MENEGHETTI, A. Filosofia Ontopsicológica. 5. ed. Recanto Maestro: Ontopsicológica Editora Universitária, 2015a.

MENEGHETTI, A. Campo Semântico. 4. ed. Recanto Maestro: Ontopsicológica Editora Universitária, $2015 \mathrm{~b}$.

MENEGHETTI, A. O Em Si do homem. 5. ed. Recanto Maestro: Ontopsicológica Editora Universitária, 2015c.

MENEGHETTI, A. O monitor de deflexão na psique humana. 3. ed. Recanto Maestro: Ontopsicológica Editora Universitária, 2017.

NASCIMENTO JÚNIOR, A. F. Fragmentos da construção histórica do pensamento neoempirista. Revista Ciência \& Educação, v. 5. N. 1, p. 37-54, 1998.

NICOLESCU, B. O Manifesto da Transdisciplinaridade. São Paulo: Triom, 1999.

RIBEIRO. T. A. N. Fenomenologia e Transdisciplinaridade: contribuições para a formação em Psicologia. Projeto de Pesquisa para Dissertação de Mestrado, Instituto de Psicologia, Programa de Pós-Graduação em Psicologia, Universidade Federal de Uberlândia (UFU), Minas Gerais, 2019.

SANTOS, A. M. Nunes dos. Werner Heisenberg. Páginas de reflexão e auto-retrato. Lisboa: Gradiva, 1990.

VIDOR, A. Fenomenologia e Ontopsicologia: de Husserl a Meneghetti. Recanto Maestro: Ontopsicológica Editora Universitária, 2013. 